\title{
Using the Five-Level NPC Inverter to Improve the FOC Control of the Asynchronous Machine
}

\author{
Mouna Es-Saadi ${ }^{1}$, Mohamed Khafallah ${ }^{2}$, Hamid Chaikhy ${ }^{3}$ \\ ${ }^{1,2}$ Laboratory of Energy \& Electricals Systems (LESE).ENSEM, Hassan II University, Morocco \\ ${ }^{3}$ Laboratoire des sciences de l'ingénieur pour l'énergie, Ecole Nationale des sciences Appliquées, \\ Université Chouaib Doukkali, Morocco
}

\begin{tabular}{l} 
Article Info \\
\hline Article history: \\
Received Sep 7, 2017 \\
Revised May 6, 2018 \\
Accepted Aug 6, 2018 \\
\hline Keyword: \\
NPC inveter \\
Railway \\
FOC \\
Induction machine \\
SPWM \\
\hline
\end{tabular}

\begin{abstract}
Many researches have been dedicated to develop the induction motor drive control strategy used on the railway traction applications. In this paper we propose to investigate and to improve the electric locomotives by using a Field Oriented Control (FOC) strategy of induction motor drive. This induction motor can be powered by a five-stage neutral point inverter controlled by sinusoidal pulse width modulation (SPWM) due to good quality for output voltage and The use of fast switches. Both conventional and improved locomotives are simulated in Matlab/Simulink and compared in open loop conditions and closed loop conditions using IP controller, in term of torque response, current harmonic distortions and rotor speed response.
\end{abstract}

Copyright $@ 2018$ Institute of Advanced Engineering and Science. All rights reserved.

\section{Corresponding Author:}

Hamid Chaikhy,

Laboratoire des sciences de l'ingénieur pour l'énergie,

Ecole Nationale des sciences Appliquées,

Route d'azzemour, Nationale N¹, Elhaouzia BP : 1166 El Jadida 24002 Maroc.

Email: chaikhy.hamid@gmail.com

\section{INTRODUCTION}

Concerns over the environment like energy prices and congestion are calling for ways to minimize economical, ecological and spatial footprint of transportation [1], During long years, Diesel engines were used for transporting goods and passengers, but nowadays they are considered to be a source of environmental disaster on wheels. Thus, there was a desire to improve the efficiency and reliability of the traction drive. This lead to the electrification of the railway system [2].

Electric traction drive has now been considered to be an efficient way of transmitting power to the traction motors that can deliver as much as two times the power output of equivalent diesel traction. It has high power-to-weight ratio which results in faster acceleration [3], but electric traction face many challenges. Especially, the improved overall performance and less vibration results in faster, more comfortable, smoother and quieter journeys for the passengers. The electric traction drives requires medium voltage and high power operation. This can be achieved with the help of multilevel inverters [4]-[6]. In fact, the aim of this work is to show the improvement of a conventional Direct field oriented control strategy induction machine performances in both steady state and transient conditions after replacing the conventional two levels inverter by an neutral point clamped inverter controlled by SPWM. In This work open and closed loop simulation results using Matlab/ Simulink are presented for a BB36000. The principle of DFOC and NPC are also presented. 


\section{PRINCIPLE OF DFOC STRATEGY FOR INDUCTION MACHINE USING TWO LEVELS \\ INVERTER}

Rotor field oriented control, as described by Blaschke, is a method of controlling a rotating field machine in such a manner to attain independent control over the torque and the flux components of the stator current [7]-[9]. Applied to induction motors, it makes it possible to control the machine in a manner similar to the control of a separately excited DC machine, and hence it enables the use of induction motors in applications requiring high-dynamic performance, where traditionally only DC drives were applied. The concept of Field-Oriented control (FOC) applied to induction motor drives, allows us to perform fast and fully decoupled control of torque and flux. To obtain such a decoupled control, FOC algorithms need to know the rotor flux angular position to correctly align the stator current vector. As a consequence it is possible to control torque and rotor flux in a DC machine control fashion, by acting on two separated components of the stator current $i_{\text {sd }}$ and $i_{s q}$ (equation (1)).

After applying the rotor field rotation (Figure 1), $\psi_{r d}^{\wedge}=\psi_{r}^{\wedge}$ and $\psi_{r q}^{\wedge}=0$. IM machine relations becomes then:

$$
\left\{\begin{array}{l}
\psi_{r d}=\frac{M}{1+p T_{r}} i_{s d} \\
T_{e}=n_{p} \frac{M}{L_{r}} \psi_{r} i_{s q}
\end{array}\right.
$$
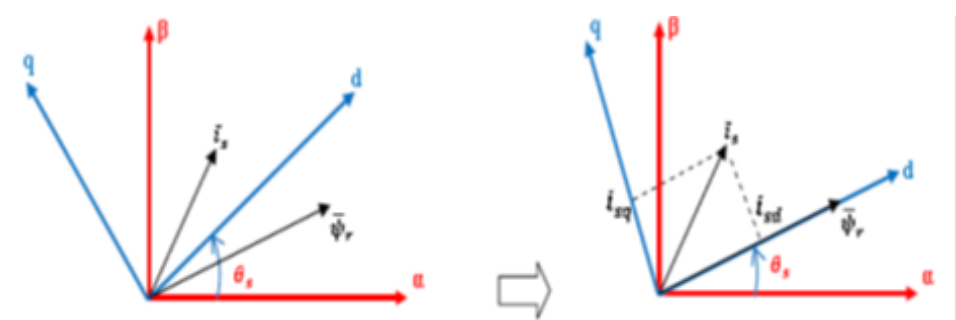

Figure. 1 Orientation of the rotor field to $d$ axis of the $(\mathrm{d}, \mathrm{q})$ reference

Before applying this orientation, the determination of rotor flux angular position is necessary. Direct field oriented control (DFOC) and Indirect field oriented control (IFOC) are the two methods used to obtain this position.

Using equation $2, \psi_{r}^{\wedge}$ and $T_{e}^{\wedge}$ are estimated using $i_{s d}$ and $i_{s q}$ respectively, and are compared to $\psi_{r}^{*}$ and $T_{e}^{*}$. As shown in Figure 2 torque and flux are directly controlled in DFOC.

$$
\left\{\begin{array}{c}
v_{s d}=\left[\left(R_{s}+p \sigma \mathfrak{Q}_{s}\right) \frac{\left(1+T_{r} p\right)}{\mathcal{M}}+\frac{\mathcal{M}}{\mathfrak{S}_{r} p}\right] \psi_{r d}-w_{s} \mathfrak{Q}_{s} \sigma i_{s q} \\
v_{s q}=\left(R_{s}+p \sigma \mathfrak{Q}_{s}\right) \frac{T_{e}}{p_{\frac{M}{L_{r}}} \psi_{r d}}+w_{s} \mathfrak{Q}_{s} \sigma i_{s d}+w_{s} \frac{\mathcal{M}}{\mathfrak{S}_{r}} \psi_{r} \\
\psi_{r}^{\wedge}=\frac{M}{1+p T_{r}} i_{s d} \\
T_{e}^{\wedge}=n_{p} \frac{M}{L_{r}} \psi_{r} i_{s q} \\
\theta_{s}=\int\left(n_{p} \Omega+\frac{M}{T_{r}} \frac{i_{s q}^{*}}{\psi_{r d}^{*}}\right) d t
\end{array}\right.
$$

Figure 2 shows the control strategy scheme of DFOC: 


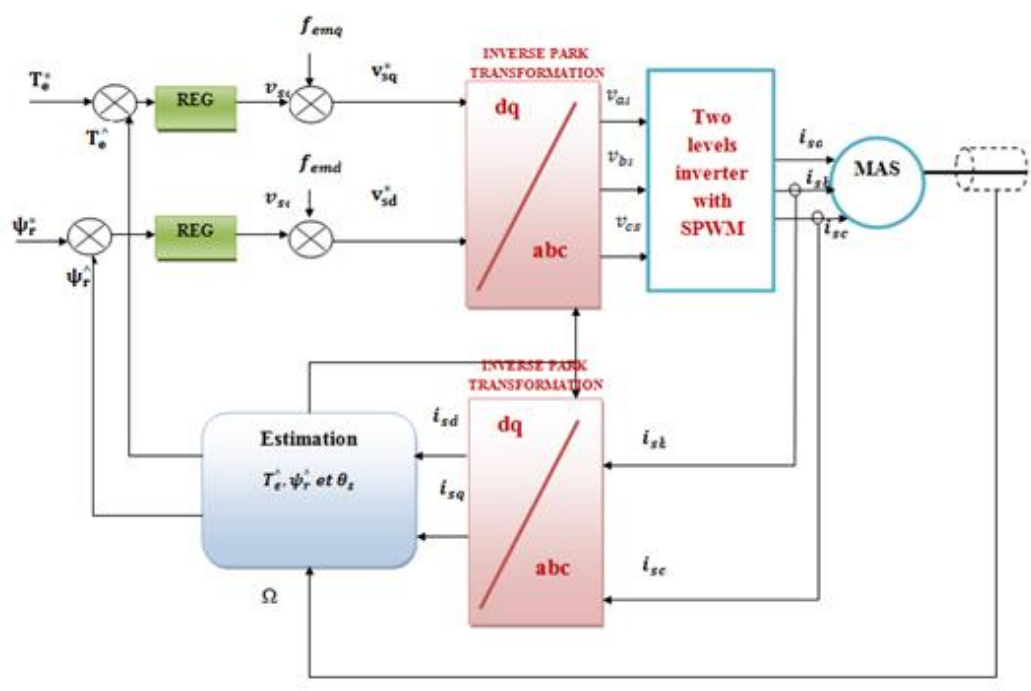

Figure 2. Direct Field oriented control strategy scheme of IM using two level inverter

To ensure decoupled control for torque and flux, ompensation terms $\mathrm{f}_{\text {emd }}$ and $\mathrm{f}_{\text {emq }}$ (equation 3 ) are added to obtain a $\mathrm{d}$ and $\mathrm{q}$ axes completely independent.

$$
\left\{\begin{array}{c}
f_{\text {emd }}=w_{s} \mathfrak{Q}_{s} \sigma i_{s q} \\
f_{\text {emq }}=w_{s} \mathfrak{Q}_{s} \sigma i_{s d}+w_{s} \frac{\mathcal{M}}{\mathfrak{R}_{r}} \psi_{r}
\end{array}\right.
$$

Equation 2 shows that how position $\theta_{\mathrm{s}}$ and voltages $\mathrm{v}_{\mathrm{sq}}, \mathrm{v}_{\mathrm{sd}}$ are calculated. Using Park position $\theta_{\mathrm{s}}$, $\mathrm{v}_{\mathrm{sq}}$, andv $\mathrm{v}_{\mathrm{sd}}$ are transformed and injected to the two levels inverter. A sinusoidal pulse width modulation is used to control this inverter (Figure 3). In SPWM modulation, Pulses resulting from the comparison between a sinusoidal reference signal and triangular carrier are injected to the switches, to obtain two voltage levels.

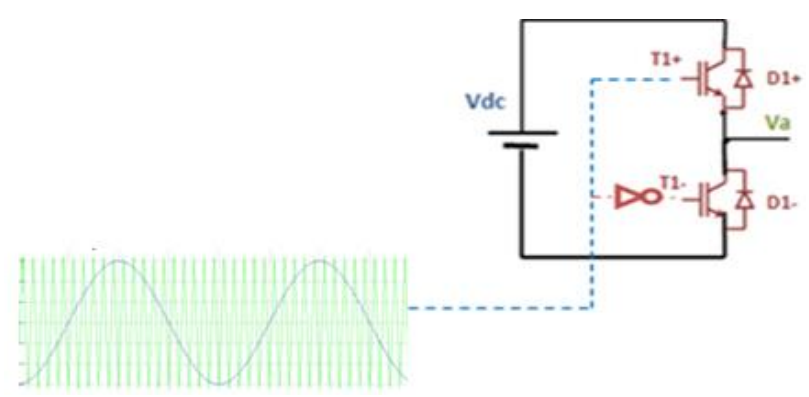

Figure 3. Principle of the SPWM two levels control strategy

\section{IMPROVEMENT OF DFOC STRATEGY FOR IM}

Multilevel conversion structures constitute a solution to improve the performances given by the classical structures with two voltages levels. For medium voltage high power applications as railway traction applications, the cost of semiconductor devices is increased. Multilevel structures offer a reduction of the voltage stress that compensates for the increased number of devices [10],[11]. Also this structures offer the advantage of reducing the size of the output filter by lowering the total harmonic content. Then, torque ripples for motor drive applications will be reduced. Even if, Stack Cell and Neutral point piloted inverters have a wide industrial spread mostly in medium voltage applications. They have disadvantages like unequal switches losses distribution. To solve this problem, NPC inverter is the multilevel inverter chosen to be used to replace the two levels inverter [12],[13]. 


\subsection{Principle of the five level NPC inverter}

As shown in Figure 4, each leg of the NPC inverter contains six clamped diodes and eight other vertical IGBTs. To obtain the five voltage levels, switches are following switching states as shown in Table 1. Figure 5 shows the four carriers SPWM control strategy using for one leg of the NPC inverter [14],[15].

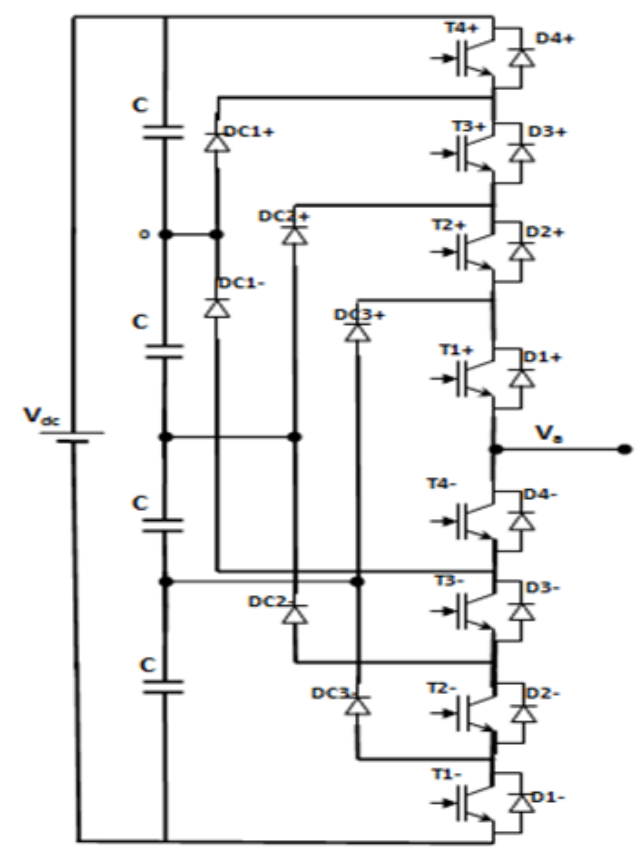

Figure. 4.Structure of a five-level NPC inverelur brush

Table 1. Basic switching of the five levels NPC inverter

\begin{tabular}{ccccccccc}
\hline \multirow{2}{*}{ Voltage Va } & $\mathrm{T} 42+$ & $\mathrm{T} 3+$ & $\mathrm{T} 2+$ & $\mathrm{T} 1+$ & $\mathrm{T} 42-$ & $\mathrm{T} 3-$ & $\mathrm{T} 2-$ & $\mathrm{T} 1-$ \\
\hline $\mathrm{Vdc} / 4$ & 1 & 1 & 1 & 1 & 0 & 0 & 0 & 0 \\
$\mathrm{Vdc} / 2$ & 0 & 1 & 1 & 1 & 1 & 0 & 0 & 0 \\
0 & 0 & 0 & 1 & 1 & 1 & 1 & 0 & 0 \\
$\mathrm{Vdc} / 4$ & 0 & 0 & 0 & 1 & 1 & 1 & 1 & 0 \\
$-\mathrm{Vdc} / 2$ & 0 & 0 & 0 & 0 & 1 & 1 & 1 & 1 \\
\hline
\end{tabular}

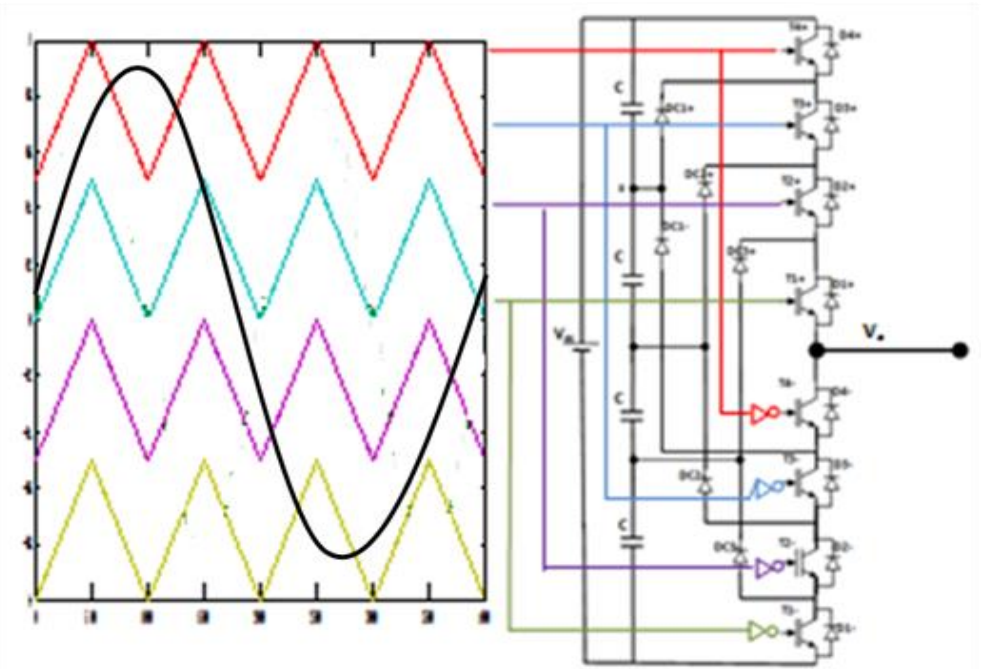

Figure 5. SPWM of the NPC 5-level inverter 
The Figure 6 shows the output voltages of the five levels NPC inverter silimulated in matlab / simulink where we observed the five voltage levels.
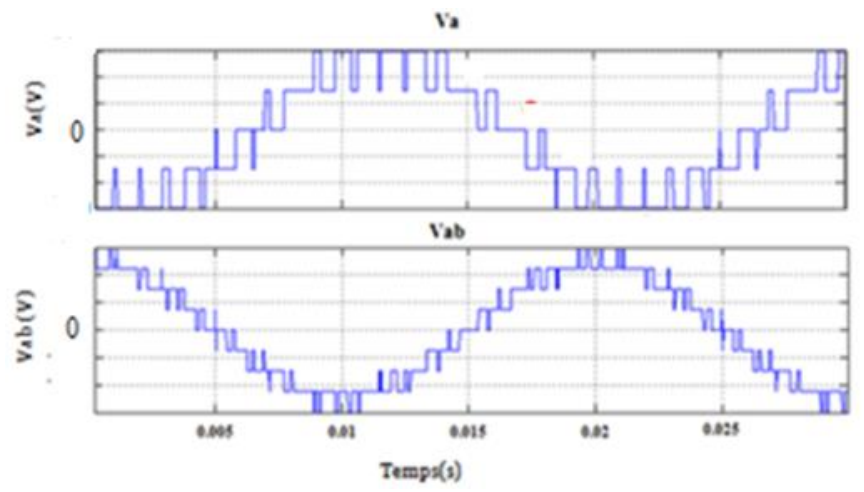

Figure 6. Output voltages of the five levels NPC inverter

\subsection{Improvement of DFOC strategy using NPC five levels inverter}

To improve the transient and steady state performances of DFOC strategy for IM, and to reduce voltage stress in semiconductors especially for high power applications, instead of the two levels inverter a five levels NPC inverter is used with an appropriate SPWM control strategy. As shown in Figure 7, all the other blocks of DFOC strategy scheme still unchangeable [16].

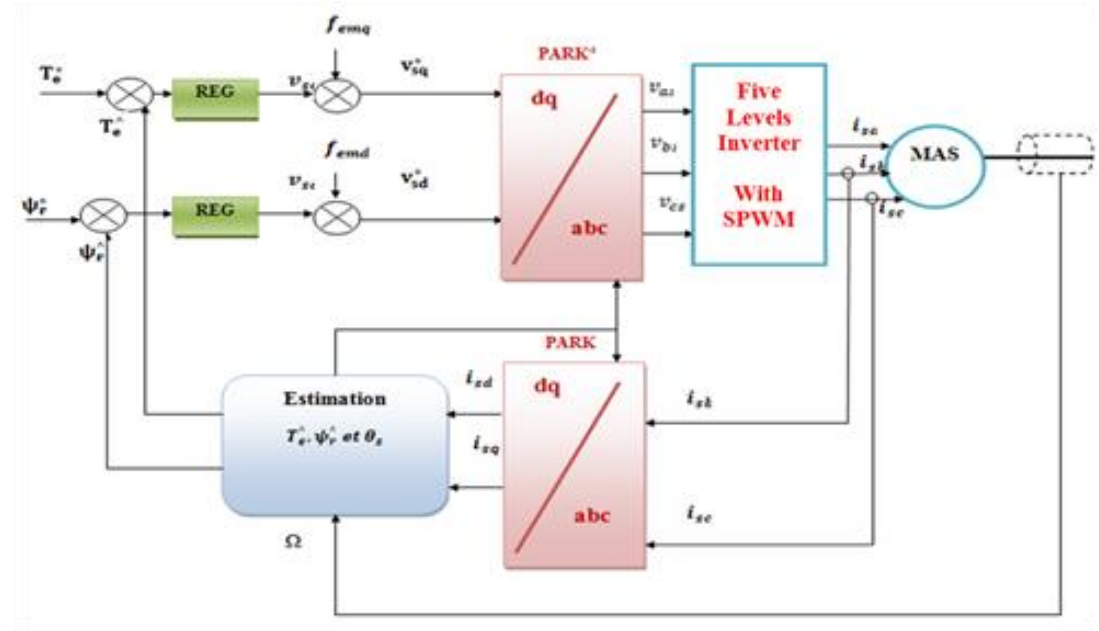

Figure 7. Field oriented control strategy scheme of IM using five level inverter NPC

\section{SIMULATION RESULTS AND DISCUSSION}

To verify effectiveness of using five levels NPC inverter, simulations are made for a high power medium voltage application which is railway traction application. A simulation test on the BB 36000 locomotive induction machine with parameters presented in TABLE. 6 has been performed.

In this section the two strategies: DFOC of IM supplied by two levels inverter 2L_DFOC and DFOC of IM supplied by NPC five levels inverter 5L_DFOC are compared following method as shown below: In open loop conditions:

a. Steady state performance: The two strategies are compared in term of current and torque ripples.

b. Transient performance: The two Strategies are compared in term of Time response to a step variation of the torque command.

In closed loop conditions:

a. The two strategies are compared in term of pursuit of the rotor speed to the speed reference for different speed variation.

Using the Five-Level NPC Inverter to Improve the FOC Control of the Asynchronous .... (Mouna Es-Saadi) 
b. The two strategies are compared in term of behavior of speed under perturbations.

\subsection{Open loop conditions}

\subsubsection{Steady state performance}

The steady-state performance of 2L_DFOC and 5L_DFOC schemes has been compared evaluating current distortions and torque ripples. Table 2 presents a comparison between the two strategies in term of current THD in different torque values: $100 \%, 50 \%$ and $-50 \%$ of the rated torque. As shown in this table THD still the same for $2 \mathrm{~L}_{-}$DFOC for the three torque values, but it is reduced to the half for the $5 \mathrm{~L}_{-}$DFOC control strategy. As presented in Figure 8, Three levels NPC used in the 5L_DFOC reduce current distortions. Thereby, torque ripples are reduced to the half of $2 L_{-}$DFOC torque ripples value as shown Table 3 .

Table 2. Current THD for 2L_DFOC and 5L_DFOC at different torque value

\begin{tabular}{ccc}
\hline THD & 2L_DFOC & 5L_DFOC \\
\hline 3000 & $5.81 \%$ & $1.1 \%$ \\
1500 & $5.7 \%$ & $1.2 \%$ \\
-1500 & $5.8 \%$ & $1.15 \%$ \\
\hline
\end{tabular}

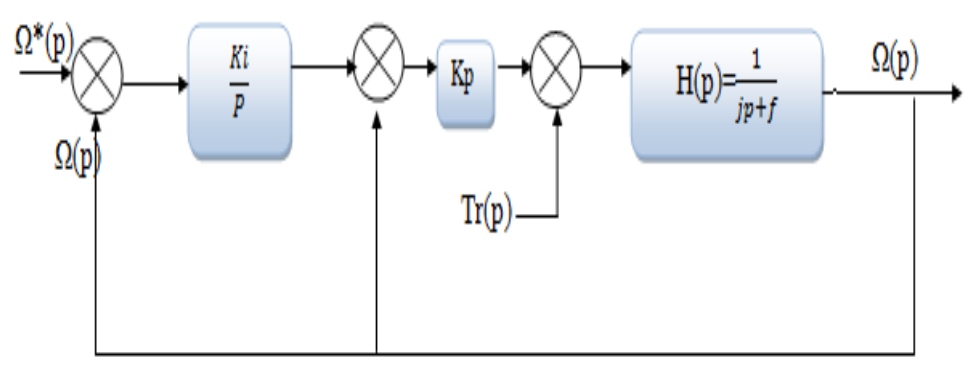

Figure 8. Closed loop IP speed controller

Table 3. Torque ripples for 2L_DFOC and 5L_DFOC at different speed value

\begin{tabular}{ccc}
\hline Torque $($ N.m) & 2L_DFOC & 5L_DFOC \\
\hline 3000 & $13 \%$ & $4 \%$ \\
1500 & $13 \%$ & $4 \%$ \\
-1500 & $13 \%$ & $4 \%$ \\
\hline
\end{tabular}

\subsubsection{Transient performance}

For different torque values, time response still the same, even if the two levels inverter is replaced by an NPC five levels inverter.

Table 4. Time response for 2L_DFOC and 5L_DFOC at different torque value

\begin{tabular}{ccc}
\hline Torque $($ N.m $)$ & 2L_DFOC & 5L_DFOC \\
\hline 3000 & $10 \mathrm{~ms}$ & $10 \mathrm{~ms}$ \\
1500 & $10 \mathrm{~ms}$ & $10 \mathrm{~ms}$ \\
-1500 & $10 \mathrm{~ms}$ & $10 \mathrm{~ms}$ \\
\hline
\end{tabular}

\subsubsection{Closed loop conditions}

The rotor speed closed loop DFOC system with IP controller is presented in Figure 9 and IP controller scheme is presented in Figure 8. 


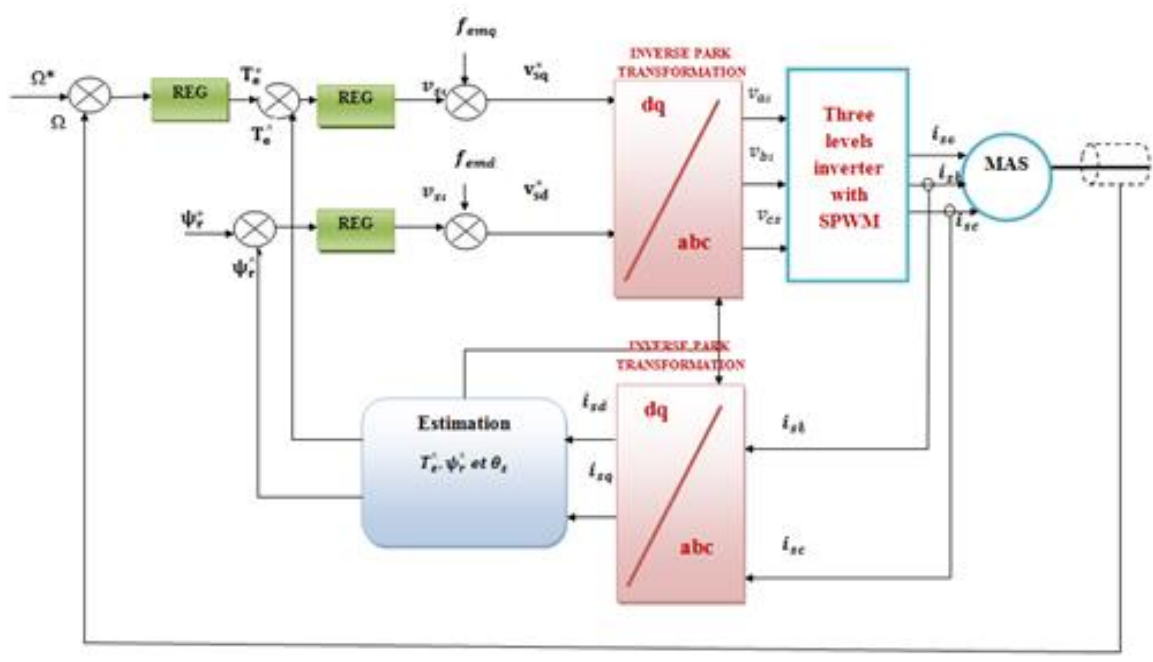

Figure 9. The rotor speed closed loop 5L_DFOC system with IP controller

In order to have an aperiodic of the above presented system, we found:

$K_{i}=\frac{1}{4 g \tau}$ and $K_{p}=\frac{J-\tau f}{\tau}$

Where: $\tau=\frac{\mathrm{J}}{\mathrm{K}_{\mathrm{p}}+\mathrm{f}}$ and $\mathrm{g}=\frac{\mathrm{K}_{\mathrm{p}}}{\mathrm{K}_{\mathrm{p}}+\mathrm{f}}$

As shown in Figure 10, the rotor speed reference is varying from 70 rd.s-1 to 150 rd.s-1(rated speed) to -70 rd.s-1. For both 2L_DFOC and 5L_DFOC strategy, rotor speed is following the rotor speed reference. Even with applying a torque load variation from 500 N.m to 1000 N.m to the two closed loop systems, this perturbation is directly rejected. Then, for 2L_DFOC and 5L_DFOC, rotor speeds follow again their references after 50ms. Finally, a detailed comparison of DFOC 2L_DFOC and 5L_DFOC is summarized in Table 5 .

Table 5. Detailed comparison between 2L_DFOC and 5L_DFOC

\begin{tabular}{lcc}
\hline \multicolumn{1}{c}{ Performances } & 2L_DFOC & 5L_DFOC \\
\hline Total switches number & 6 & and 18 diodes \\
Off-state voltage & $\mathrm{V}_{\mathrm{dc}}$ & $\frac{\text { Vdc }}{4}$ \\
Complexity of implementation & simple & difficult \\
Current distortions & Not good & Good \\
Torque ripples & (Around 5.7\%) & (Around 1.1\%) \\
Response to a torque step variation & more & less \\
Pursuit of the rotor speed & Very good & Fast (10ms) \\
Behavior of & Very good \\
Speed under perturbations. & Good & Good \\
\hline
\end{tabular}


Table 6. Induction machine and simulation parameters

\begin{tabular}{|c|c|c|}
\hline \multicolumn{2}{|c|}{ Parameters } & Signification \\
\hline \multirow{7}{*}{ 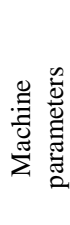 } & $\mathrm{Rs}=0.012$ & Stator resistance $(\Omega)$ \\
\hline & $\mathrm{Rr}=0.012$ & Rotor resistance $(\Omega)$ \\
\hline & $\mathrm{M}=0.0135$ & Mutual inductance $(\mathrm{H})$ \\
\hline & $\mathrm{Ls}=0.0137$ & Stator inductance $(\mathrm{H})$ \\
\hline & $\mathrm{Lr}=0.0137$ & Rotor inductance $(\mathrm{H})$ \\
\hline & $\mathrm{J}=10$ & Factor of inertia $\left(\mathrm{Kg} \cdot \mathrm{m}^{2}\right)$ \\
\hline & $\mathrm{f}=0.0024$ & Coefficient of friction \\
\hline \multirow{7}{*}{ 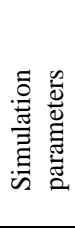 } & $\mathrm{p}=2$ & Number of pole pairs \\
\hline & $\mathrm{P}=1.5$ & Rated power (MW) \\
\hline & $V=2070$ & Phase voltage at $220 \mathrm{Km} / \mathrm{h}(\mathrm{V})$ \\
\hline & $\mathrm{V}_{\mathrm{dc}}=2400$ & DC bus voltage $(\mathrm{V})$ \\
\hline & $F_{p w m}=2000$ & Pulse width modulation frequency $(\mathrm{Hz})$ \\
\hline & $C_{\text {nom }}=3000$ & Rated torque(N.m) \\
\hline & $\Omega_{\text {nom }}=435$ & Rated speed ( $\mathrm{rad} / \mathrm{s})$ \\
\hline
\end{tabular}

2L_DFOC

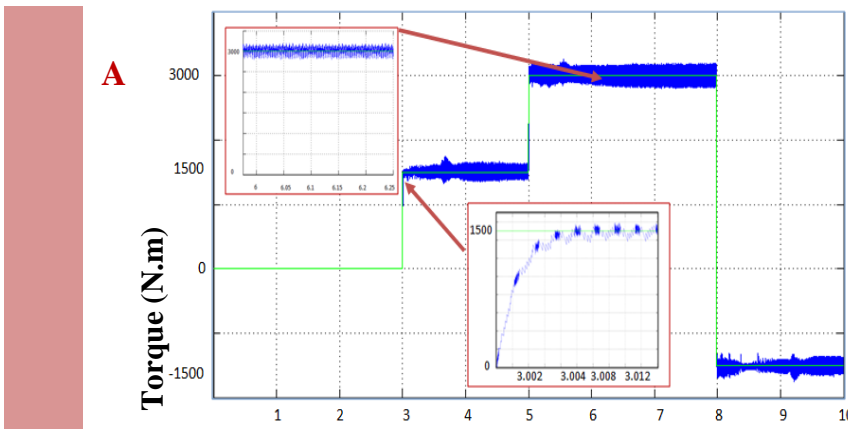

Time (s)

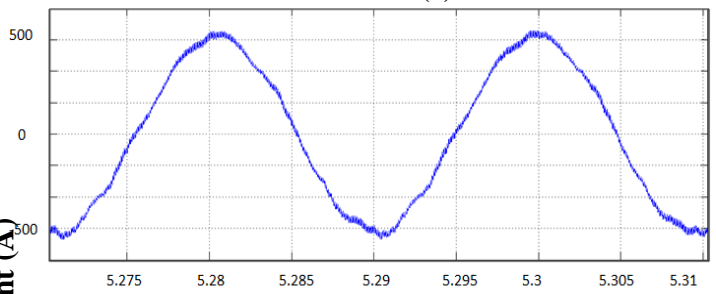

Time (s)

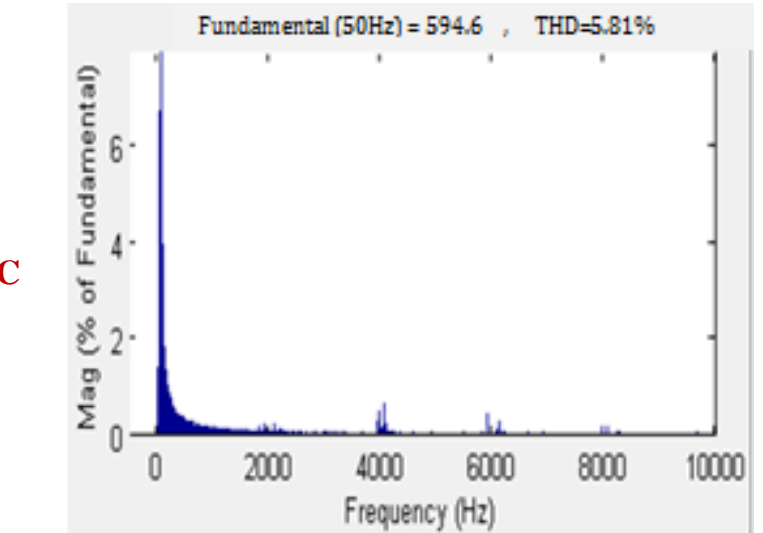

5L_DFOC
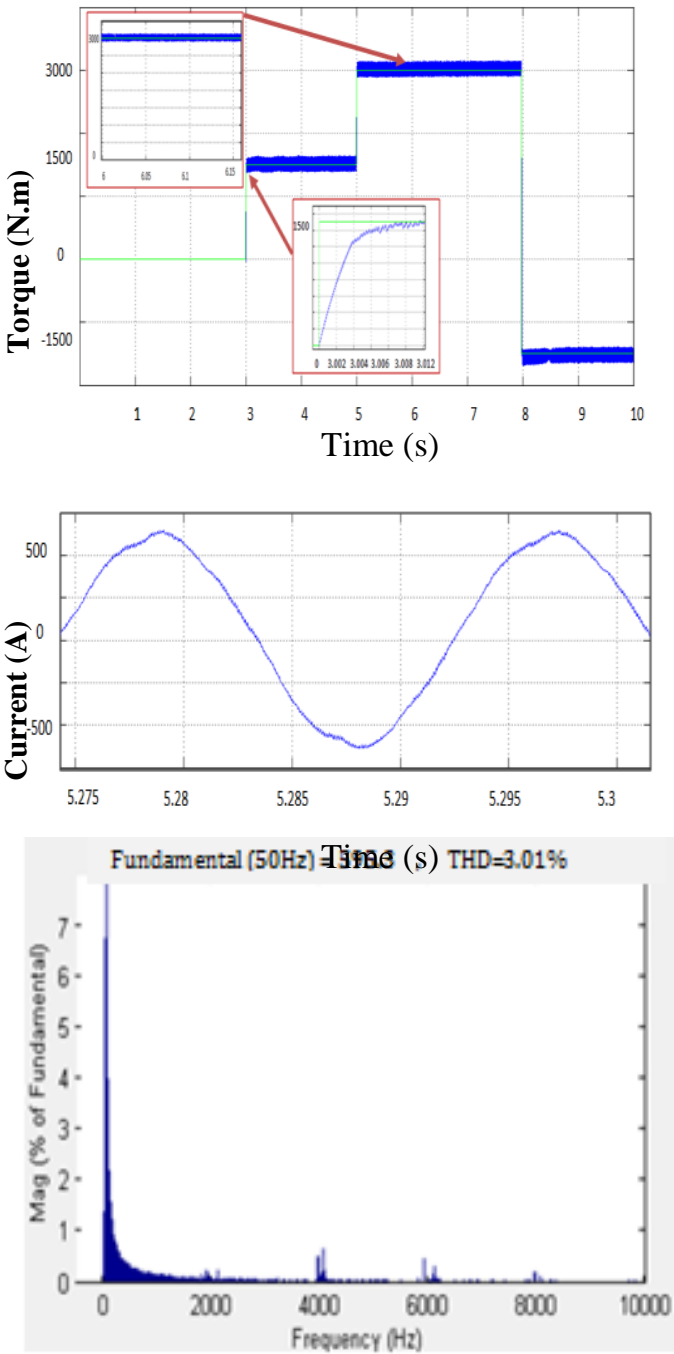


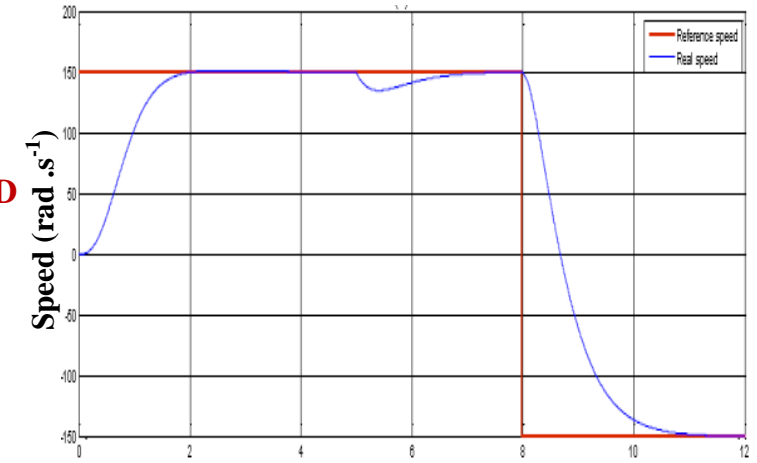

Time (s)

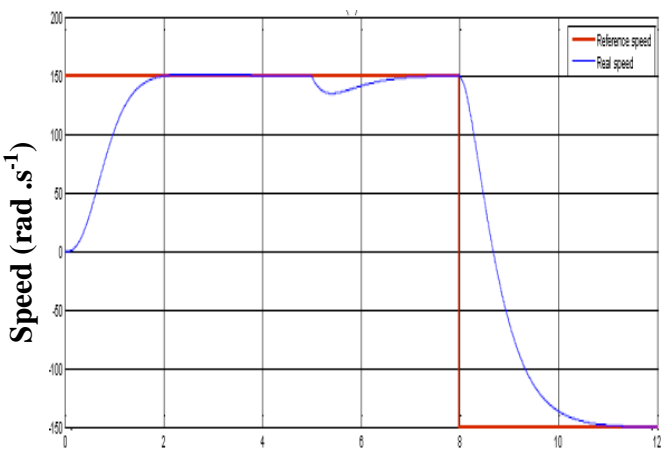

Time (s)

Figure 10. Detailed comparison between 2L_DFOC and 5L_DFOC in open and closed loop conditions in term of A.Torque ripple, B. Current THD, C. Torque response, D. Speed response

\section{CONCLUSION}

This work present a detailed comparison between 2L_DFOC and 3L_DFOC using an ANPC inverter. The two strategies used a high power application: railway traction, to present performances in both open and closed loop conditions. As presented previously, the use of a multilevel inverter decrease current distortions and torque ripples, but all the other performances still the same. The aim of our future work is to improve 3L_DFOC by using space vector modulation instead of sinusoidal modulation control of the ANPC inverter.

\section{REFERENCES}

[1] A. Moglestue, "ABB Revue,” The corporate technical journal, 2010.

[2] V. Sabaté, "Traction électrique ferroviaire," Techniques de l'ingénieur, 2008.

[3] F. Lacôte, et al., "Traction électrique ferroviaire:introduction," Techniques de l'ingénieur, 2008.

[4] A. Jeunesse and M. Debruyne, "BB36000 locomotive multi-tensions européene," $R C C$, vol. 9, 1998.

[5] J. Manguelle, "Convertisseurs multi-niveaux asymétriques alimentés par transformateurs multi-secondaires basse fréquence : Réaction au réseau d'alimentation," Thèse de doctorat en génie électrique, Ecole Polytechnique Fédérale de Lausane, 2004.

[6] J. Rodriguez, et al., "A survey on neutral-point-clamped inverters," IEEE Trans. Ind. Electron., vol. 7, pp. 22192230, 2010.

[7] H. Chaikhy, et al., "Evaluation des performances des commandes vectorielles de la machine à induction," Revue de génie industriel, vol. 6, pp. 23-32, 2011.

[8] F. Blaschke, "A new method for the structural decoupling of A.C. induction machines," Conf. Rec. IFAC, Duesseldorf, Germany, pp. 1-15, 1971.

[9] Ch. Benzazah, et al., International Journal of Innovation and Applied Studies, vol/issue: 9(2), pp. 841-852, 2014.

[10] N. Schibili, et al., "A Three-Phase Multilevel Converter for High-Power Induction Motors On Power Elect., vol/issue: 13(5), 1998.

[11] S. R. Pulikanti, et al., "SHE-PWM switching strategies for Active Neutral Point Clamped Multilevel Converters," AUPEC, 2008.

[12] X. Jing, et al., "Application and losses analysis of ANPC converters in doubly fed induction generator wind energy conversion system," IEEE Trans, pp. 131-138, 2013.

[13] T. Geyer, "Model predictive direct torque control of a five level ANPC converter drive system," IEEE Transactions on Industry Applications, vol/issue: 48(5), 2012.

[14] J. Rodriguez, et al., "Multilevel Inverters; a survey of topologies, controls, and applications," IEEE Trans. Ind. Electron., vol/issue: 49(4), pp. 724-738, 2002.

[15] F. Kieferndorf, et al., "ANPC-5L technology applied to medium-voltage variable-speed drives applications," International Symposium on Power Electronics, Electrical Drives, Automation and Motion, Pisa, Italy, 2010.

[16] T. Bruckner, et al., "Feed farward loss control of three level active 3L_NPC converters," IEEE Trans. on Ind. Appl., vol/issue: 43(6), pp. 1588-1596, 2007. 


\section{BIOGRAPHIES OF AUTHORS}

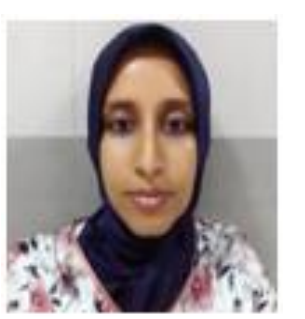

Mouna Es-saadi was born in Morocco in 1985. He received Electrical engineering from the university of Cadi Ayyad, Marrakech, from university of Ibn Zohr, Agadir in 2009. She worked two years as electrical engineer in LEONI and Bontaz Morocco .His currently working toward the doctorate degree in Electrical engineering at ENSEM of the Hassan II university, Casablanca. His current research interests are the areas of energy efficiency, applications of power electronics and motor drives

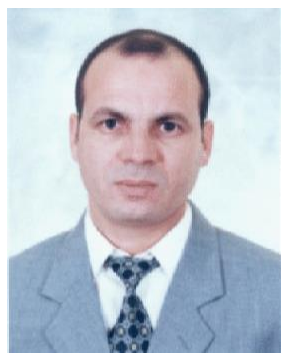

Mohamed Khafallah was born in Morocco in 1964. He received B.Sc., M.Sc. and Doctorate degrees from Hassan II University, Casablanca II, in 1989, 1991 and 1995 respectively, all in Electrical Engineering. In 1995 he joined the Department of Electrical Engineering at the National School of Electricity and Mechanics (ENSEM), Hassan II University, Casablanca. His current research interests are in the application of power electronics converts and motor drives. m_khafallah@yahoo.fr

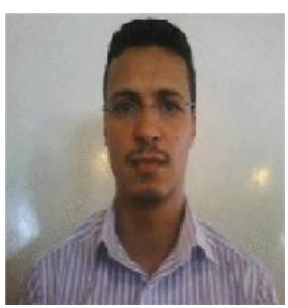

Hamid Chaikhy was born in Morocco in 1975. He received B.Sc., M. Sc. degrees at ENSET from the University of Hassan II, Mohammedia in 1998, from University of Ibno Zohr, Agadir in 2005 respectively, all in Electrical Engineering. He is currently working towards the Doctorate degree in Electrical Engineering at the institute of electrical and mechanical engineering (ENSEM) of the University of Hassan II, Casablanca I. His current research interests are the areas of field oriented controllers and motor drives. Chaikhy.hamid@gmail.com 